\title{
CAPSULE COMMENTARY \\ Capsule Commentary on Kata et al., Advance Care Planning Prior to Death in Older Adults with Hip Fracture
}

\author{
Stephanie Nothelle, MD \\ Division of Geriatric Medicine and Gerontology, Johns Hopkins School of Medicine, Baltimore, MD, USA.
}

J Gen Intern Med 35(7):2248

DOI: $10.1007 / \mathrm{s} 11606-020-05705-5$

(C) Society of General Internal Medicine 2020

$\mathrm{K}$ ata et al. ${ }^{1}$ use the Health and Retirement Survey (HRS), linked to Medicare claims to estimate the prevalence of advance care planning (ACP) discussions prior to death from any cause in older adults who had a hip fracture. Incident hip fracture was determined using Medicare claims while completion of ACP was determined by proxy report in the HRS exit survey after participant death. The authors found that a quarter of all older adults who died and had hip fracture did not have an ACP prior to death. Furthermore, of the $32 \%$ of older adults who lacked capacity to make decisions at the end of life, one in five did not have an ACP. Completion of ACP prior to death was associated with sociodemographic factors such as race and educational attainment but not with clinical factors such as age or comorbidity.

The inability to capture whether ACP occurred in all older adults with hip fracture, rather than only those who died and the average time from hip fracture to death of three years makes it difficult to know whether the hip fracture itself prompted ACP. Furthermore, ACP completion was assessed by asking about formal documentation of ACP, meaning informal discussions may have been missed. Informal discussions may have been adequate and having the discussion itself is an important ACP outcome. ${ }^{2,3}$ Regardless, this study provides novel and important information about how often ACP is addressed in older adults who die after hip fracture, an important and potentially overlooked population for ACP.

Given the growing older adult population and the ability to bill Medicare for ACP discussions, this study calls clinicians'

Published online February 19, 2020 attention to the opportunity and need to discuss ACP with older adults who face an acute event, such as hip fracture. Although not a new finding, ${ }^{4}$ the association between sociodemographic factors and decreased ACP completion and lack of association between clinical factors and ACP completion provides an agenda for clinicians designing quality improvement initiatives and researchers designing interventions aimed at improving ACP completion about the need to specifically target these disparities.

Corresponding Author: Stephanie Nothelle, MD; Division of Geriatric Medicine and Gerontology Johns Hopkins School of Medicine, Baltimore, MD, USA (e-mail: Snothel1@jhmi.edu).

\section{Compliance with Ethical Standards:}

Conflict of Interest: The author declares that she does not have a conflict of interest.

\section{REFERENCES}

1. Kata A, Cenzer I, Sudore R, Covinsky K, Tang V Advance Care Planning Prior to Death in Older Adults with Hip Fracture. J Gen Intern Med. https://doi.org/10.1007/s11606-020-05644-1 .

2. Sudore RL, Fried TR Redefining the "Planning" in Advance Care Planning: Preparing for End-of-Life Decision Making. Ann Intern Med 2010; 153(4): 256-261.

3. Sudore RL, Heyland DK, Lum HD, Rietjens JAC, Korfage IJ, Ritchie CS, Hanson LC, Meier DE, Pantilat SZ, Lorenz K, Howard M, Green MJ, Simon JE, Feuz MA, You JJ. Outcomes That Define Successful Advance Care Planning: A Delphi Panel Consensus. J Pain Symptom Manag. 2018;55(2):245-255.e8. doi:https://doi.org/10.1016/j.jpainsymman. 2017.08.025.

4. Harrison KL, Adrion ER, Ritchie CS, Sudore RL, Smith AK Low completion and disparities in advance care planning activities among older Medicare beneficiaries. JAMA Int Med 2016;176(12):1872-1875.

Publisher's Note Springer Nature remains neutral with regard to jurisdictional claims in published maps and institutional affiliations. 